\title{
Etika Komunikasi dalam Media Sosial Sesuai \\ Tuntutan Al-Qur an
}

\section{Rinwanto}

Institut Agama Islam Nahdlatul Ulama Tuban

Email: Rinwanto808@gmail.com

\section{Hidayatus Sholihah}

Lembaga Pengembangan Tilawatil Qur,'anb(LPTQ) Rengel

Email: hidayatussholihah1112@gmail.com

\section{Nurul Hakim}

Institut Agama Islam Nahdlatul Ulama Tuban

Email: nurulhakim283@gmail.com

\section{Mufid Syakhlani}

Institut Agama Islam Sunan Giri Ponorogo

mengajinusantara25@gmail.com

\begin{abstract}
This paper discusses the phenomenon of the development of communication tools in the ancient era until it has grown rapidly until now. Many uncovered stories that are not true from people who are not responsible, either from certain groups or from personal interests. Communication from social media is very dangerous if it is not accompanied by proper ethics in communicating, especially in social media. AS-Syaukani, for example, defines the keyword al-bayan as the ability to communicate. Besides that, in the al-quran there is another keyword, namely qoul. The commands to say in the al-quran and hadith are an indication of the obligation for Muslims to apply the nature of honesty and correct speech which in the concept of al-quran is known as qaulan sadidan.
\end{abstract}

Keywords: Ethics, Communication, Al-Qur'an

\begin{abstract}
Makalah ini membahas tentang fenomena perkembangan alat komunikasi diera zaman dulu sampai berkembang pesat sampai sekarang. Banyak ditemukannya berita-berita yang tidak benar dari orang-orang yang tidak bertanggung jawab, entah dari kelompok-kelompok tertentu atau dari kepentingan pribadi. Komunikasi dari media sosial sangatlah berbahaya jika tanpa di dampingi etika yang benar dalam berkomunikasi khususnya dimedia sosial. AS-Syaukani misalnya mengartikan kata kunci al-bayan sebagai kemampuan berkomunikasi. Selain itu dalam al-qur'an terdapat kata kunci lain yaitu qoul. Perintah berkata dalam al-qur'an dan hadist menjadi sebuah indikasi wajibnya bagi muslim untuk mengaplikasikan sifat kejujuran dan perkataan benar yang dalam konsep al-qur'an dikenal dengan istilah qaulan sadidan.
\end{abstract}

Kata Kunci: Etika, Komunikasi, Al-Qur'an 


\section{Pendahuluan}

Tantangan diera media sosial pada saat ini adalah bagaimana masyarakat bisa menggunakan media sosial ini kepada hal-hal yang positif terutama dalam berkomunikasi.

"Dahulu sebelum berkembangnya media sosial, pusat utama komunikasi di Dunia Islam hanyalah masjid dan sangat terbatas, khususnya diwaktu-waktu pertemuan harian, sholat lima waktu hari jum 'at" (Johan, 2001).

Tetapi, Pada saat ini perkembangan komunikasi sangatlah pesat tidak harus bertatap muka sudah bisa berkomunikasi satu sama lain. Dengan Kemajuan baru membawa kita pada fenomena yang baru pula. Cara berinteraksi ditempat yang berbeda karena adanya media sosial dapat terhubung satu sama lain.

Namun, karena kemajuan zaman perkembangan komunikasi banyak yang disalah gunakan sehingga dapat merobek sekat-sekat budaya dan geografis dengan amat bebas. Tersebarnya berita-berita dari orang-orang yang tidak bertanggung jawab yang dapat memecah belah satu sama lain. Dalam hal ini perlu adanya etika dalam bernedia sosial yang benar sesuai dengan tuntunan al-qur'an dan hadist. Dalam al-qur'an telah disebutkan beberapa prinsip-prinsip berkomunikasi dengan benar.

Maka dari itu perlu adanya untuk kita menyaring berita yang didapat terutama dari media sosial yang masih belum jelas sumbernya. Etika bermedia sosial sangatlah ditekan karena melihat banyaknya dampak negatif yang terjadi. Serta bebasnya berkomunikasi yang menyebabkan budaya asing yang telah menyebar luas di sekitar kita. Hal ini membuat peneliti untuk mencari beberapa rumusan masalah sebagai berikut Apa yang dimaksud Etika dan Komunikasi dan Apa saja ayat-ayat al-qur'an yang membahas tentang etika berkomunikasi. Dalam penelitian ini tentunya peneliti memiliki beberapa tujuan yaitu untuk memahami apa yang dimaksud dengan etika dan komunikasi dan juga ntuk mengetahui ayat-ayat al-qur'an yang membahas tentang etika berkomunikasi. Sedangkan diharapkan dengan adanya tulisan ini dapat bermanfaat menambah referensi yang sesuai dengan tema penelitian yaitu "Etika Komunikasi”.

\section{Etika}

"Istilah Etika berasal dari Yunani yaitu "ethos" dalam bentuk tunggal yang artinya tempat tinggal yang biasa, padang rumput, kandang, kebiasaan,adat, akhlak,watak, perasaan, sikap dan cara berfikir. Dalam bentuk Jamak (ta etha) yang bermakna adat kebiasaan. Dan artiterakhir inilah yang menjadikan latar belakang bagi terbentuknya istilah etika oleh filsuf Yunani Aristoteles (384-332 S.M) Sudah dipakai untuk menunjukkan filsafat moral" (K.Bertens, h 4).

Jika melihat dari Kamus Besar Bahasa Indonesia yang baru (Departemen pendidikan kebudayaan, 1998) dijelaskan bahwasanya etika dapat dibedakan dalam tiga arti yaitu:

“a) Ilmu Tentang apa yang baik dan apa yang buruk dan tentang hak dan kewajiban moral atau akhlak. b) Kumpulan asas atau nilai yang berkenaan dengan akhlak, c) 
Nilai yang berkenaan mengenai benar dan salah yang dianut golongan atau masyarakat"'(Berten,h 5).

Dalam karyanyanya K. Bertens disini membahas tentang bagaimana menghadapi adanya berbagai kegiatanyang khususnya dalam menghadapi kemajuan ilmu dan teknologi. Menurut K. Bertens etika juga berkaitan dengan ilmu moral sebagaimana untuk rule of control dalam diri manusia dalam segala konteks. tanpa adanya etika manusia tidak memiliki control dalam dirinya ketika bersikap.

Etika dalam Islam tidak jauh berbeda dengan akhlaq yang tidak bisa lepas dari dalam diri manusia. Ilmu akhlak itu sendiri adalah salah satu cabang ilmu yang pengetahuan dalam agama Islam yang disitu ilmu akhlak disinonimkan dengan etika. Oleh dari itu etika berperan sangat penting bagi setiap diri manusia. Dalam etika dan akhlak sama-sama mengkaji tentang baik buruknya tingkah laku seseorang terhadap orang lainnya (Hamzah, hal 12). Adapun redaksi hadist yang membahas tentang etika adalah sebagai berikut:

"Telah menceritakan kepada kami Muhammad bin "Abd Allah bin Numayr: Telah menceritakan kepada kami Abu Mu'awiyah dan waki' keduanya berkata "Telah menceritakan kepada kami al-'Amash, Demikian juga dieiwayatkan dari jalur lainnya, dan telah menceritakan kepada kami Abu Kurayb; Telah menceritakan kepada kami Allah dia berkata; Rasulullah Saw bersabda: "Kalian haus berlaku jujur karena kejujuran itu akan membimbing kepada kebaikan. Dan kebaikan itu akan membimbing ke surga. Seseorang yang senantiasa berlaku jujur dan memelihara kejujuran, maka ia akan dicatat sebagai orang yang jujur disisi Allah. Dan hindarilah dusta, karena kedustaan itu akan menggiring kepada kejahatan dan kejahatan itu akan menjerumuskan ke neraka. Seseorang yang senantiasa berdusta dan memelihara kedustaan, maka ia akan dicatat sebagai pendusta disisi Allah" (Salahudin, 2010).

Untuk mencapai pemaknaan yang benar terhadap hadist tentang etika bermedia sosial, penulis mencoba mengaitkannya dengan al-qur'an. Karena salah satu cara untuk memahami hadist adalah dengan menyandingkan dengan ayat-ayat al-qur'an, dan melihat ada atau tidaknya hal yang bertentangan dengan nass al-qur'an apabila itu bertentangan, maka sudah jelas hasit tersebut ditolak. Kalaupun nanti ada pertentangan, perlulah melangkah pada dua tinjauan. Yang pertama yaitu meninjaudari segi datang riwayatnya ( wurud) dan yang kedua yakni meninjau dari segi dilalah al-ma'na atau konteks makna (Yusuf, 1999).

Maka dari itu, perlu adanya sebuah pembuktian bahwasanya hadist ini tidak memiliki pertentangan dengan nass al-qur'an. Hadist ini mempunyai tema besar yaitu kejujuran. Adapun kejujuran sebagaimana telah kita ketahui bahwasanya banyak disebutkan dalam ayat al-qur'an yang berbicara mengenai etika terutama tentang kejujuran. Disinilah pendekatan pendekatan agama diperlukan untuk melihat dan memberikan pedoman bagaimana etika dan prinsip dalam bermedia sosial yang baik dalam menerima informasi ataupun menyebarkannya. Misalnya saja, 
kita dapat mengambil nila dasar tabayyun yang secara eksplisit digambarkan dalam al-qur'an pada surah Al-Hujurat ayat 6:

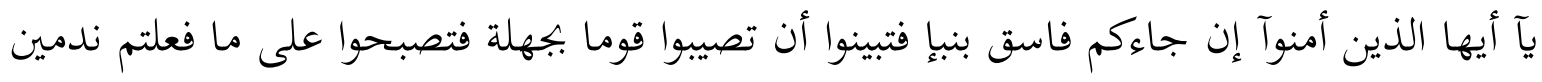

Artinya:

Hai orang-orang yang beriman, jika datang kepadamu orang fasik membawa suatu berita, maka periksalah dengan teliti agar kamu tidak menimpakan suatu musbah kepada suatu kaum tanpa mengetahui keadaannya yang menyebabkan kamu menyesal atas perbuatanmu itu. (QS. Al-Hujurat: 6).

Ayat diatas memuat nilai dasar bermedia sosial berupa transparansi dan klarifikasi berita yang kemudian menjadi peraturan konkret tentang larangan menyebarkan suatu berita sebelum diketahui validitas sumbernya. Setelah nilai dasar tabayyun tersebut, kita dapat menggali lebih banyak lagi nilai dasar Islam yang dapat dijadikan acuan, seperti prinsip keadilan sebagai dasar untuk membuat asas umum dalam menerima informasi secara berimbang, prinsip ukhuwah sebagai dasar asas umum kesopanan dan kesantunan dalam berdiskusi dan lain sebagainya.

Namun, kemajuan teknologi bukan untuk dihindari tapi untuk disikapi. Al-qur'an berasal dari yang Maha Baik tentunya mengajarkan etika yang baik. Sebagai makhluk berakal, seharusnya manusia mampu memahami, menilai dan mengkritisi informasi yang disebarkan melalui teknologi. Sayangnya banyak manusia yang terhegemoni untuk menyebarkan informasi yang tidak bisa di pertanggung jawabkan.

\section{Komunikasi}

Al-Qur'an menyebutkan bahwa komunikasi adalah salah satu fitrah manusia. Dengan komunikasi manusia dapat mengekspresikan dirinya dan membentuk jaringan interaksi untuk berkomunikasi sosial guna mengembangkan kepribadiannya. Dalam berkomunikasi sangat berperan penting dalam kehidupan antar manusia satu dengan yang lainnya. Bahkan para pakar psikologpun setuju kegagalan dalam berkomunikasi dangat berdampak fatal terhadap individual maupun sosial (Syawir, 2014).

Kegagalan secara individual dapat menimbulkan frustasi, demoralisasi dan penyakitpenyakit jiwa lainnya. Sedangkan dampak dari kegagalan secara sosial dapat menghambat kerja sama, dapat menghambat toleransi dan merintangi norma-norma sosial. Adapun dalam al-qur'an terdapat penggalan ayat dari surah Ar-Rahman ayat1-4 yang menjelaskan tentang komunikasi. Berikut ayat surah Ar-Rahman ayat 1-4:

$$
\text { الرحمن (1) علم القرآن (2) خلق الإنسان (3) علمه البيان (4) }
$$


Artinya:

Tuhan yang maha pemurah (1) Yang telah mengajarkan Al-Qur'an (2) Dia menciptakan manusia (3) Mengajarkan pandai berbicara (4).

"Al-Syaukani dalam tafsir fath al-qadir mengartikan al-bayan dari surah Ar-Rahman sebagai makna berkomunikasi. Untuk mengetahui bagaimana orang-orang seharusnya berkomunikasi secara benar (qoulan sadidan) yang harus dilacak melalui kunci yang dipergunakan al-qur'an untuk berkomunikasi. Selain "al-bayan” juga ada kunci lain dalam al-qir'an yaitu "al-qoul" dalam konteks "amr" dapat disimpulkan bahwa ada enam prinsip dalam al-qur'an yakni qoulan sadidan, qoulan balighan, qoulan mansyuran, qoulan layyinan, qoulan kariman dan qoulan makrufan"(Imam Ash-Syaukani,jilid 5).

\section{Media Sosial}

Beberapa penelitian yang berhubungan dengan media sosial diantaranya adalah: pertama artikel al-qur'an "al-qur'an dizaman media sosial" yang ditulis oleh mutimmatun nadhifah. Didalam tulisannya ini dibahas tentang transformasi perilaku terhadap al-qur'an. Dulu al-que'an hanya dalam bentuk mushaf saja namun sekarang al-qur'an sudah bisa diakses aplikasi diperangkat elektronik.

Buku yang ditulis oleh Prof. H. Nadirsyah Hosen, ph D. Tafsir al-qur'an dimedsos. Buku ini berisikan kompilasi kajian-kajian didalam buku ini dijelaskan secara tematik. Diantaranya mengenai "Rahasia menghayatikitab suci al-qur'an". Dan juga tentang "Tafsir ayat-ayat politik".

Dari beberapa telaah yang telah penulis sebutkan diatas dapat disimpulkan bahwa kajiankajian sebelumnya sama sekali sangat berbeda dengan kajian yanag akan penulis teliti. Seperti tulisan Abdul Rahman dan Ulfah Nur'aeni yang membahas komunikasi tanpa konteks komunikasi tertentu. Sedangkan penulis membahas tentang komununikasi dalam konteks bermedia sosial.

Media sosial disebut juga dengan New media, karena media sosial menawakan digitization, convergensi, interactivity, dan development of network terkait pembuatan pesan yang penyampaian pesannya. Kemamppuannya dalam menawarkan interaktifitas ini yang membuat ketertarikan dari orang-orang, karena memungkinkan para pengguna new media ini mengonsumsi informasi-informasi yang dihasilkan dan yang juga diingnkannya. Kemampuan dalam menawarkan interactivity inilah yang menjadi fokus dan konsep dari new media (Ernika, 2011).

Media sosial dapat dikelompokkan menjadi beberapa bagian besar yaitu:

a) social network, media sosial untuk bersosialisasi dan berinteraksi ( facebook, myspace, hi5,linked in,bebo dll)

b) discuss, media sosial yang memfasilitasi sekelompok orang untuk melakukan obrolan dan diskusi (google talk, yahoo M,skype,phorum,dll). 
c) share, media sosial yang mmefasilitasi kita untuk saling berbagi file,Vidio,music, dll ( youtube, slideshare,feedback,flickr,crowdstorm, dll).

d) publish (wordpredss, Wikipedia, blog, wikia, dig, dll).

e) social game, media sosial berupa game yang dapat dilakukan atau dimainkan bersama-sama (congregate,doof, pogo,café,com dll).

f) micro blog (twitter, plurk, pownce, twirxr, plazes, tweetpeek).

Sosial media memiliki dampak besar pada kehidupan manusia di era sekarang. Apabila kita dapat memanfaatkan media dengan baik dan benar media sosial dapat menjadi media untuk pemasaran, dagang dan mencari koneksi serta untuk memperluas pertemanan. Namun tidak sedikit pula kerugian ketika kita menggunakan sosial media secara berlebihan. Seperti halnya kecanduan, sulit bergaul didunia nyata dan lain sebagainya.

\section{Etika berkomunikasi dalam Al-qur'an}

Dalam berkomunikasi ada beberapa cara untuk menutupi kebenaran dalam dengan berkomunikasi yakni a) menutupi kebenaran dengan kata-kata yang abstrak, ambigu atau yang menimbulkan penafsiran yang sangat berlainan apabila tidak setuju atau memiliki pandangan lain pada lawan bicaranya. Contohnya ketika seorang muballigh menemukan pendapat lain dan pendapatnya tidak logis iya akan berkata "akal harus tunduk dengan agama" dia sebenarnya mau mengatakan bahwa logika orang lain itu harus tunduk dengan pemahamannya tentang agama. Akal dan agama adalah duakata yang abstrak. Oleh karena itu, menasehatkan agar kita berhatihati dalam menggunakan kata-kata abstrak. b) orang menutupi kebenaran dengan menciptakan istilah yang diberi makna orang lain. Istilah itu berupa eufimisme atau pemutar balikan makna sama sekali. Pejabat melaporkan kelaparan didaerahnya dengan mengatakan "kasus kekurangan gizi atau "rawan pangan". Ia tidak dikatakan "ditangkap" tetapi diamankan. Harga tidak dinaikkan tetapi di "sesuaikan". Nabi Muhammad Saw bersabda sebagaimana diriwayatkan di Bukhori- Muslim sebagai berikut:

Artinya:

Dari ibnu Mas'ud ra dari Nabi Saw bersabda sesungguhnya kebenaran itu membawa pada kebaikan dan kebaikan itu membawa surga. Seseorang akan selalu bertindak jujur sehingga ditulis disisi Allah SWT sebagai orang yang jujur. Dan sesungguhnya yang dusta itu membawa pada kejahatan dan kejahatan itu membawa ke neraka. Seseorang selalu berdusta sehingga ia ditulis disisi Allah sebagai pendusta.

Dalam berkomunikasi untuk mencapai pemaknaan yang benar terhadap makna etika berkomunikasi yang telah disinggung dalam Surah Ar-Rahman bahwasanya komunikasi 
memiliki enam prinsip dalam al-qur'an dan berikut adalah ayat-ayat yang menjelaskan tentang enam prinsip komunikasi tersebut:

\section{a) Qoulan sadidan}

qoulan sadidan dalam al-qur'an disebut dua kali yakni :

yang pertama, Allah menyuruh manusia menyampaikan qoulan sadidan (perkataan yang benar) dalam urusan anak yatim dan keturunan yakni QS. 4:9 sebagai berikut:

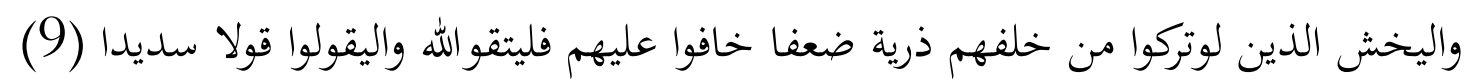

Terjemahan:

"Dan hendaklah taku kepada Allah orang-orang yang seandainya meninggalkan dibelakang mereka anak-anak yang lemah, yang mereka khawatir terhadap (kesejahteraan) mereka. Oleh sebab itu hendaklah mereka bertakwa kepada Allah dan hendaklah mereka mengucapkan perkataan yang benar".

Yang kedua, Allah memerintahkan qoulan sesudah bertakwa. Sebagaimana dalam firman Allah QS. 33/70:

$$
\text { يا أيهالنين آمنوا إتقوالله وقولوا قولا سديدا (70) }
$$

Terjemahan:

"Hai orang-orang yang beriman, bertakwalah kamu kepada Allah dan katakanlah perkataan yang benar".

Dari dua ayat diatas dapat ditarik kesimpulan bahwasanya Allah memerintahkan manusia untuk senantiasa bertakwa yang harus di barengi dengan perkataan yang benar adanya. Allah akan senantiasa memberikan balasan sesuai dengan amal-amal yang telah di perbuat dan Allah akan mengampuni dosamu. Barang siapa yang taat dan bertakwa kepada Allah niscaya akan memeperoleh keberuntungan yang berlimpah. Berkata dengan benar adalah prinsip komunikasi yang terkandung dalam Al-Qur'an dan mengandung makna dan pengertian yang benar.

b) Qoulan Balighan

Qoulan Balighan diungkapkan bahwa secara bahasa bermakna perkataan yang sampai kepada maksud dan berpengaruh sehingga membekas dijiwa. Dalam Al-qur'an Qoulan Balighan di ungkapkan dalam surah An-Nisa' ayat 63. Berikut ayatnya:

$$
\text { أولئك الذين يعلم الله مافي قلوبهم فأعرض عنهم وقل لمم في أنفسكم قولا بليغا }
$$


Terjemahan:

"Mereka itu adalah orang-orang yang Allah mengetahui apa yang ada dalam hati mereka. Karena itu berpalinglah kamu dari mereka dan berilah mereka pelajaran dan katakanlah kepada mereka perkataan yang berbekas dalam jiwa mereka".

Dari ayat diatas menjelaskan bahwasanya etika dalam berkomunikasi yang baik salah satunya adalah prinsip Qoulan Balighan yaitu perkataan yang memiliki maksud dan tujuan yang jelas. Berkata hingga berbekas dijiwa yang dimaksud disini adalah perkataan yang memiliki makna yang jelas sehingga lawan dalam berkomunikasi dapan menangkap dan bahkan mengingat didalam jiwa mereka.

c) Qoulan mansyuran

Qoulan mansyuran menurut bahasa memiliki makna perkataan yang mudah. Mansyur adalah isim maf'ul dari yusr yang artinya mudah. Ungkapan ini terdapat dalam surah Al-Isro' ayat 28 Allah berfirman:

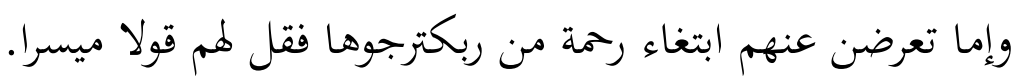

Terjemahan:

"Dan jika kamu berpaling dari mereka untuk memperoleh rahmat dari Tuhanmu yang kamu harapkan, maka katakanlah kepada mereka ucapan yang pantas".

Dari ayat diatas dapat disimpulkan bahwasanya dalam etika berkomunikasi berkatalah yang mudah dipahami oleh lawan bicaramya. Dengan menerapkan prinsip ini dapat berkata dengan bahasa yang mudah dimengerti sangatlah penting. Karena jika lawan komunikasinya tidak memahami yang disampaikan maka akan menimpulkan kesalah fahaman.

d) Qoulan layyinan

Qoulan layyinan dalam bahasa memiliki makna yang lembut dan ungkapan ini disampaikan dalam Al-qur'an surah Thaha ayat 44. Allah SWT berfirman:

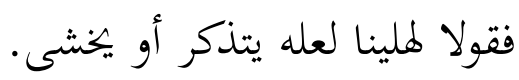

Terjemahan:

"Maka berbicaralah kamu berdua kepadanya dengan kata-kata yang lemah lembut mudahmudahan ia ingat atau takut".

Dalam surah diatas memiliki kesimpulan bahwa etika berkomunikasi memiliki prinsip berkata dengan lemah lembut. Dalam prinsip Qoulan layyinan ini menganjurkan unuk kita menggunkan bahasa yang lemah lembut agar tidak menyinggung perasaan lawan bicara kita.

e) Qoulan kariman 
Qoulan kariman secara bahasa bermakna perkataan yang muliadan berharga. Lawan dari kata yang mulia atau berharga adalah murahan atau tidak punya nilai. Ungkapan ini diabadikan oleh Allah dalam Al-qur'an surah Al-Isro' ayat 23 Allah berfirman:

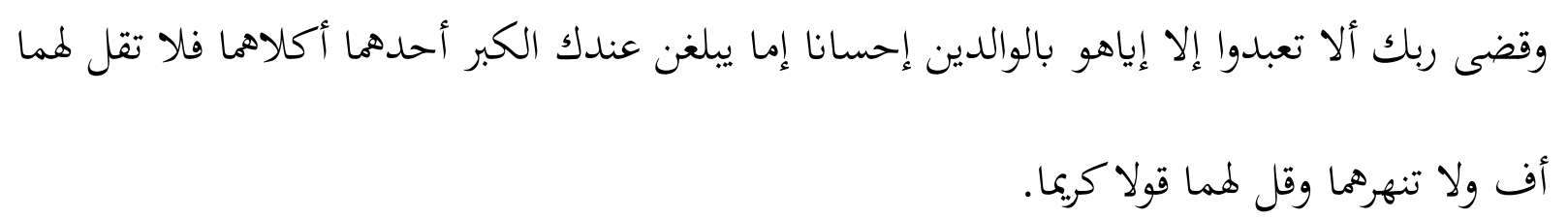

Terjemahan:

"Dan Tuhanmu telah memerintahkan supaya kamu jangan menyembah selain Dia dan hendaklah kamu berbuat baik kepada ibu dan bapakmu dengan sebaik-baiknya. Jika salah seorang dai keduanya sampai berumur lanjut dalam pemeliharamu, maka sekali-kali janganlah kamu berkata "aah" dan janganlah kamu membentak dan ucapkanlah kepada mereka perkataan yang mulia".

Dari ayat di atas dapat ditarik kesimpulan bahwasanya prinsip etika erkomunikasi salah satunya adalah Qoulan kariman yaitu berkata dengan berharga atau yang mulia. Seperti halnya ketika berkata dengan orang tua harus menggunakan kata-kata yang mulia agartidak menyakiti hati orang tua. Kata"ah" dalam ayat diatas adalah kata yang tidak sopan ketika harus diucapkan kepada orang tua. Jadi, gunakanlah kata yang mulia untuk siapapun sesuai dengan prinsi ini.

\section{f) Qoulan makrufan}

Qoulan makrufan memiliki makna kebaikan dunia dan akhirat (Sayyed al-Alusi, Jus 3). Ungkapan kali ini disebutkan dalam al-qur'an dengan menampilkan empat peristiwa yang berbeda-beda dan salah satu dari empat itu adalah Surah Al-baqarah ayat 235:

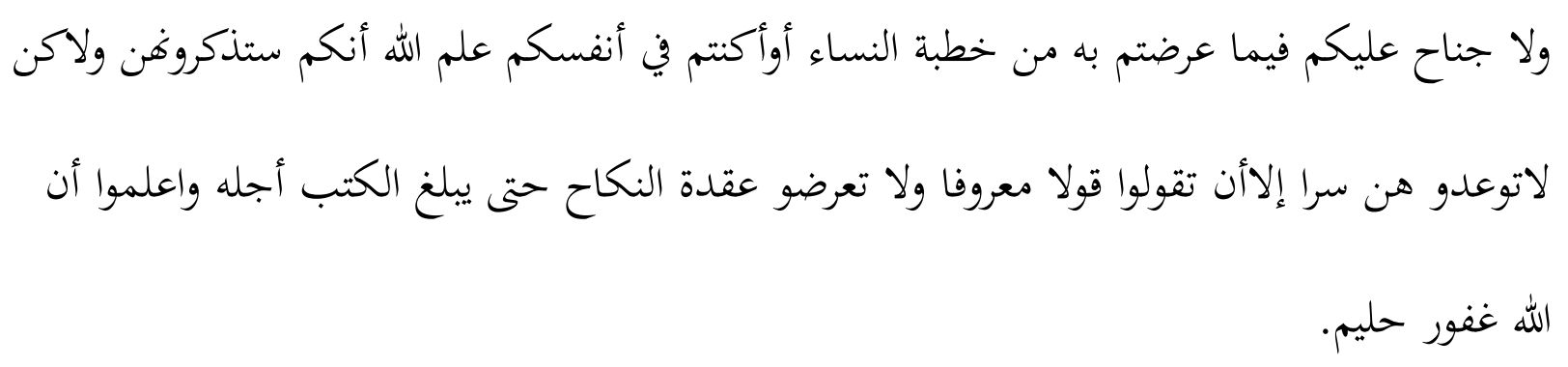

Terjemahan:

"Dan tidak ada dosa bagi kamu meminang wanita-wanita itu dengan sindiran atau kamu menyembunyikan dalam hatinya. Allah mengetahui bahwa kamu akan menyebut-nyebut mereka. Pada itu janganlah kamu mengadakan janji kawin dengan mereka dengan rahasia, kecuali sekedar mengucapkan perkataan yang ma'ruf dan janganlah kamu berazam untuk bertiqad nikah sebelum habis iddahnya. Dan ketahuilah bahwasanya Allah mengetahui apa 
yang ada dalam hatimu maka takutlah kepada-Nya dan ketahuilah bahwa Allah Maha Pengampun lagi Maha Penyantun".

Dari penjelasan diatas dapat ditarik kesimpulan bahwa etika berkomunikasi berpengaruh terhadap kebaikan dunia dan akhirat. Karena semua perkataan akan dipertanggung jawabkan yang tidak hanya di dunia namun juga di akhirat. Walaupun berusaha menyembunyikan kebenaran sehingga mengatakan sesuatau yang tidak sesuai dengan yang ada sesunggunya Allah Maha mengetahui dan Maha pengampun.

Selain ayat-ayat diatas yang menjelaskan tentang etika berkomunikasi terdapat beberapa ayat al-qur'an yang berkaitan dengan etika bermedia sosial dan fenomena terhadap berita yang bohong sebagai berikut:

a. Surah Al-Taubah ayat 119

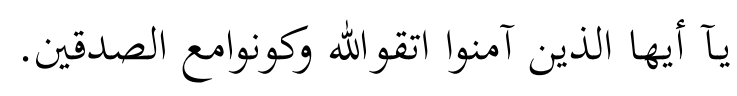

Terjemah:

"Hai orang-orang yang beriman bertakwalah kepada Allah dan hendaklah kamu bersama orang-orang yang benar" (Al-Qur'an, 119).

b. Surah Al-Maidah ayat 8

$$
\text { يآ أيها الذين آمنوا كونوا قوامين لله شهداء بالقسط ولا يجرمنكم شنآن قور على ألا تعدلوا عدلوا هو }
$$

Terjemahan:

"Hai orang-orang yang beriman hendaklah kamu jadi orang-orang yang selalu menegakkan kebenaran karena Allah, menjadi saksi dengan adil. Dan sekali-kali kebencianmu terhadap sesuatu kaum, mendorong kamu untuk berlaku tidak adil. Berlaku adillah karena adil itu lebih dekat kepada taqwa. Dan bertakwalah kepada Allah, Sesungguhnya Allah Maha Mengetahui apa yang kamu kerjakan" (Al-Qur'an, 8).

c. Surah An-Nahl ayat 105

$$
\text { إنما يفتري الكذب الذين لايؤمنون بآيات الله وأولئك هم الكذبون. }
$$

Terjemahan:

"Sesungguhnya yang mengada-adakan kebohongan, hanyalah orang-orang yang tidak beriman kepada ayat-ayat Allah dan mereka itulah orang-orang pendusta”.

Al-Qur'an menyuruh kita untuk selalu berkata benar. Kejujuran melahirkan kekuatan, sementara kebohongan mendatangkan kelemahan. Biasa berkata benar mencerminkan 
keberanian. Bohong sering lahir karena rendah diri, pengecut dsn ketakutan. Orang yang membuat-buat kebohongan tersebut hanyalah orang-orang yang tak berimank kepada ayat-ayat Allah. Mereka itulah pendusta. (An-Nahl 105).

Nabi Muhammad saw dengan mengutip al-qur'an menjelaskan orang beriman tidak akan berdusta. Dalam perkembangan sejarah, umat Islam sudah sering dirugikan karena berita-berita dusta. Yang paling parah terjadi, ketika bohong memasuki teks-teks suci yang menjadi rujukan. Kebohongan tidak berhasil memasuki al-qur'an karena keaslian al-qur'an dijamin oleh Allah (juga karena kaum muslimin hanya memiliki satu mushaf al-qur'an) tetapi kebohongan telah menyusup kedalam penafsiran al-qur'an. Makna al-qur'an pernah disimpangkan untuk kepentingan pribadi dan golongan.

Kebohongan juga memasuki hadist-hadist Nabi saw walaupun berdusta atas nama Nabi diancam dengan neraka.sepanjang sejarah ada saja yang berwawancara imajiner dengan Nabi. Belakangan ini ada orang yang berwawancara imajiner dengan para sahabat yang Mulia. Mereka menisbahkan kepada Nabi dan para sahabatnya prasangka, fanatisme dan kejahilan mereka. Para ahli hadist menyebut berita imajiner ini sebagai mawdhu' dan para penulisnya atau pengarangnya disebut alwadhdha atau al-kadzab (pendusta). Pada zaman Nabi mereka disebut al-fasiq.

Pada zaman sahabat ada murid sahabat Nabi yang pendusta, diantaranya yaituikeimah dan muqatil bin sulaiman. Ikrimah salah satunya yaitu banyak menisbahkan pendapatnya pada Ibnu abbas. Ka'ab al-akhbar banyak memasukkan mitos-mitos Yahudi dan Nasrani dalam tafsir Isra'illiyat.

Berita-berita dusta tenang Nabi sangatlah berbahaya bagi umat Islam karena umat Islam merujuk kepada Nabi dalam setiap perilaku mereka. Sunnah Nabi menjadi dasar hukum yang kedua setelah al-qur'an. Memalsukan hadist Nabi sama halnya dengan memalsukan ajaran islam. Sedangkan menyebarkan hadist mawdhu' telah banyak mengubah ajaran Islam. Imam syafi'I bercerita tentang Wahab bin Kasy'an. Ia berkata aku melihat Abdullah bin al-zubair memulai sholat jum'at sebelum khotbah. Semua sunnah Rosullullah telah diubah, bahkan sholatpun dirubah (Asy-Syafi'I, hal 208).

Oleh karena itu ilmu hadist sangatlah penting dan berharga untuk memelihara kemurnian Islam. Studi kritis terhadap sejarah Rosulullah akan disambut oleh setiap muslim yang mencintai kebenaran dan sekaligus dibenci oleh orang-orang yang mencemari Islam. Perintah berkata benar dalam al-qur'an dan hadist menjadi sebuah indikasi wajibnya bagi muslim mengaplikasikan sifat kejujuran dan perkataan benar. 


\section{Kesimpulan}

Kesimpulan lain dari makalah ini yang dapat penulis rangkum adalah:

Manusia adalah makhluk sosial yang tak bisa lepas dari etika dan komunikasi. Manusia dibekali dengan moral, spiritual potensi jasad, potensi sosial dan intelektual. Dengan bekal tersebut manusialah yang dipercaya dapat mengelola bumi bersama-sama. Dengan cara komunikasi satu sama lainnya. Manusia satu dengan manusia lainnya juga bersinergi untuk dapat membentuk kelompok sosial dan menerapkan bekerjasama satu sama lain. Dari sudut pandang diatas dapat ditarik kesimpulan sebagai berikut:

1. Etika dalam Islam tidak jauh berbeda dengan akhlaq yang tidak bisa lepas dari dalam diri manusia. Ilmu akhlak itu sendiri adalah salah satu cabang ilmu yang pengetahuan dalam agama Islam yang disitu ilmu akhlak disinonimkan dengan etika. Oleh dari itu etika berperan sangat penting bagi setiap diri manusia. Dalam etika dan akhlak sama-sama mengkaji tentang baik buruknya tingkah laku seseorang terhadap orang lainnya.

2. Al-Qur'an menyebutkan bahwa komunikasi adalah salah satu fitrah manusia. Dengan komunikasi manusia dapat mengekspresikan dirinya dan membentuk jaringan interaksi untuk berkomunikasi sosial guna mengembangkan kepribadiannya.

3. Adapun enam prinsip etika berkomunikasi adalah sebagai berikut: aulan sadidan, qoulan balighan, qoulan mansyuran, qoulan layyinan, qoulan kariman dan qoulan makrufan. 


\section{Daftar Pustaka}

Al-Qaradawi, Yusuf Bagaimana Memahami Hadist Nabi SAW, Terj. Muhammad AlBaqir (Bandung: Karisma 1999)

Al-baghdadi, Sayyed al-alusi, Ruh ak-ma'ani fi tafsir al-qur'an al-'adzim wa al-sab'ual matsani (Beirut: Dar Al-Kutub al-ilmiyah, 1415-1994) juz 3

Bertens, K., Etika (Jakarta: PT Gramedia Pustaka Utama)

Imam As-Syaukani, Tafsir Fath al-qadir jilid 5. Beirut: Dar al-fikr, t.th

L. Esposito, John. Ensiklopedia Oxford Dunia Islam Modern (Mizan: Bandung, 2001).

Setya Watie, Errika Dwie," komunikasi dan media sosial" (communication and social media)" the messenger, vol. III, no.1, Edisi Juli 2011

Syawir Dahlan, Muh, Etika komunikasi dalam al-qur'an dan hadist (STAIN, 2014)

Ya'qub, Hamzah, Etika Islam, (Bandung: Diponegoro, 1988)

Departemen Agama RI, Al-Qur'an dan Terjemahannya, Semarang, Toha Putra 2001 Al-Qur'anul Karim 